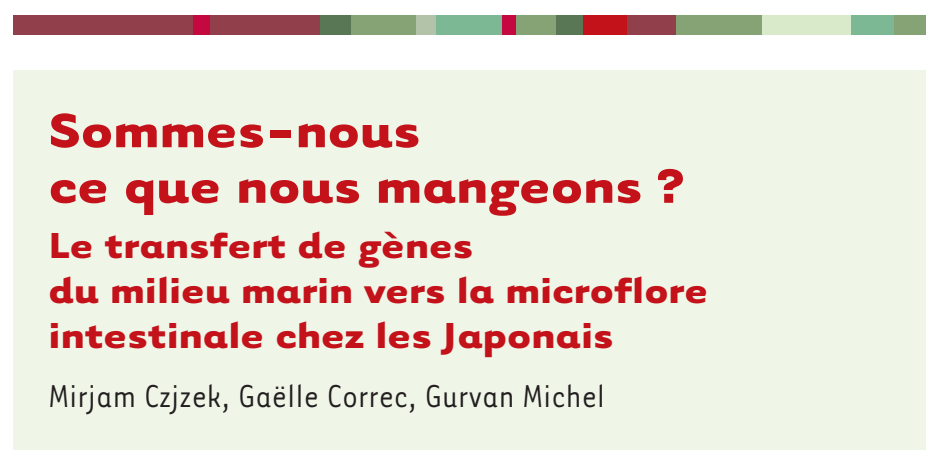

"Chaque publication scientifique ne sert qu'à poser 10, 20 questions. Chaque découverte scientifique est passionnante parce qu'elle ouvre un univers de questions. Si les questions vous angoissent, ne soyez pas scientifique. » Boris Cyrulnik

«Imaginez-vous en face d'un mets exotique, appétissant, mais qui, à cause de sa nature étrange, ne peut être mangé de façon classique. Imaginez ensuite une personne originaire du pays où ce mets est servi traditionnellement, qui vous tend des ustensiles savamment conçus qui permettent la consommation du plat sans pour autant en altérer le goût» [1]. Sans le chercher, nous sommes tombés sur un tel «échange d'ustensiles» entre des bactéries marines et des bactéries habitant l'intestin humain. Tout d'abord, nous avons découvert une nouvelle activité enzymatique [2] spécifique de la dégradation d'un polymère de sucres présent dans les algues rouges du genre Porphyra. Puis, des analyses génomiques poussées ont mis en évidence un échange de matériel génétique un transfert horizontal de gènes - de bactérie marine à bactérie intestinale, ce qui permet à cette dernière de dégrader des fibres alimentaires venant d'algues comestibles, qui autrement ne pourraient être assimilées [15] $(\rightarrow)$ Voir l'article $(\rightarrow)$.

de Simone Gilgenkrantz, page 808 de ce numéro

La microflore intestinale humaine :

la concurrence est rude

II est aujourd'hui bien connu que nos intestins hébergent une communauté dense et complexe de micro-organismes, dont l'ensemble constitue la microflore intestinale [3]. Cette microflore est constituée de centaines de millions de cellules bactériennes dont la plupart sont résidentes à long terme; mais les bactéries associées aux aliments ingérés sont des membres transitoires de cet écosystème. Toutes sont en concurrence pour des ressources limitées, principalement fournies par notre nourriture.

Le génome humain possède peu de gènes codant pour des enzymes capables de dégrader les polysaccharides de végétaux, c'est-à-dire les fibres alimentaires présentes dans tous les fruits et légumes. Ces nutriments passent donc dans la partie distale de notre tractus intestinal, où les centaines d'espèces microbiennes attendent et se «livrent une bataille féroce» pour en tirer leur énergie. $\varepsilon$ n effet, contrairement à l'homme, la plupart d'entre elles sont des championnes toutes catégories de la dégradation de ces fibres alimentaires [4] ! Elles nous aident donc à digérer ces fibres, libérant les sucres de taille adéquate pour être assimilés, ce qui nous offre ainsi une source supplémentaire d'énergie. Les bactéries de la microflore intestinale jouent ainsi un rôle très important, mais encore mal compris, pour notre santé.

Au sein de la microflore intestinale, la compétition est rude pour l'accès aux nutriments. Une stratégie possible pour un micro-organisme intestinal est donc d'acquérir une efficacité supérieure à celle des espèces concurrentes dans l'utilisation de polysaccharides particu-
CNRS-UPMC UMR7139,

Végétaux marins et biomolécules, place Georges Teissier, 29682 Roscoff, France. czjzek@sb-roscoff.fr

liers. Le transfert horizontal de gènes [5] est l'un des mécanismes qui permettent aux bactéries d'enrichir leurs collections « d'ustensiles». Si le nouvel outil confère à la bactérie un net avantage par rapport aux autres membres de la communauté, si par exemple elle est la seule à pouvoir dégrader une fibre donnée, elle va de ce fait occuper une place plus importante dans son écosystème.

Les études menées jusqu'à maintenant sur la microflore intestinale des vertébrés ont révélé plusieurs faits. La microflore intestinale est généralement dominée par des firmicutes et des bacteroïdètes, ce qui la différencie fortement des communautés bactériennes de l'environnement [6]. La composition de cette microflore varie selon les grandes catégories de régime alimentaire (régimes carnivore, herbivore et omnivore). Dans le cas des animaux herbivores et omnivores, les bactéries de la flore sont particulièrement prolixes en enzymes impliquées dans la digestion des polysaccharides de plantes terrestres [6]. Enfin les échanges de matériel génétique sont assez fréquents entre bactéries intestinales [7]. En revanche, les mécanismes par lesquels l'alimentation influe sur la microflore intestinale restent incertains. Ainsi, un régime alimentaire exotique peut-il influencer spécifiquement la microflore humaine et comment? Comme nous l'avons découvert, un tel régime a bien eu une influence sur l'évolution des bactéries intestinales, mais toutes les populations humaines ne sont pas égales face aux cuisines exotiques... 


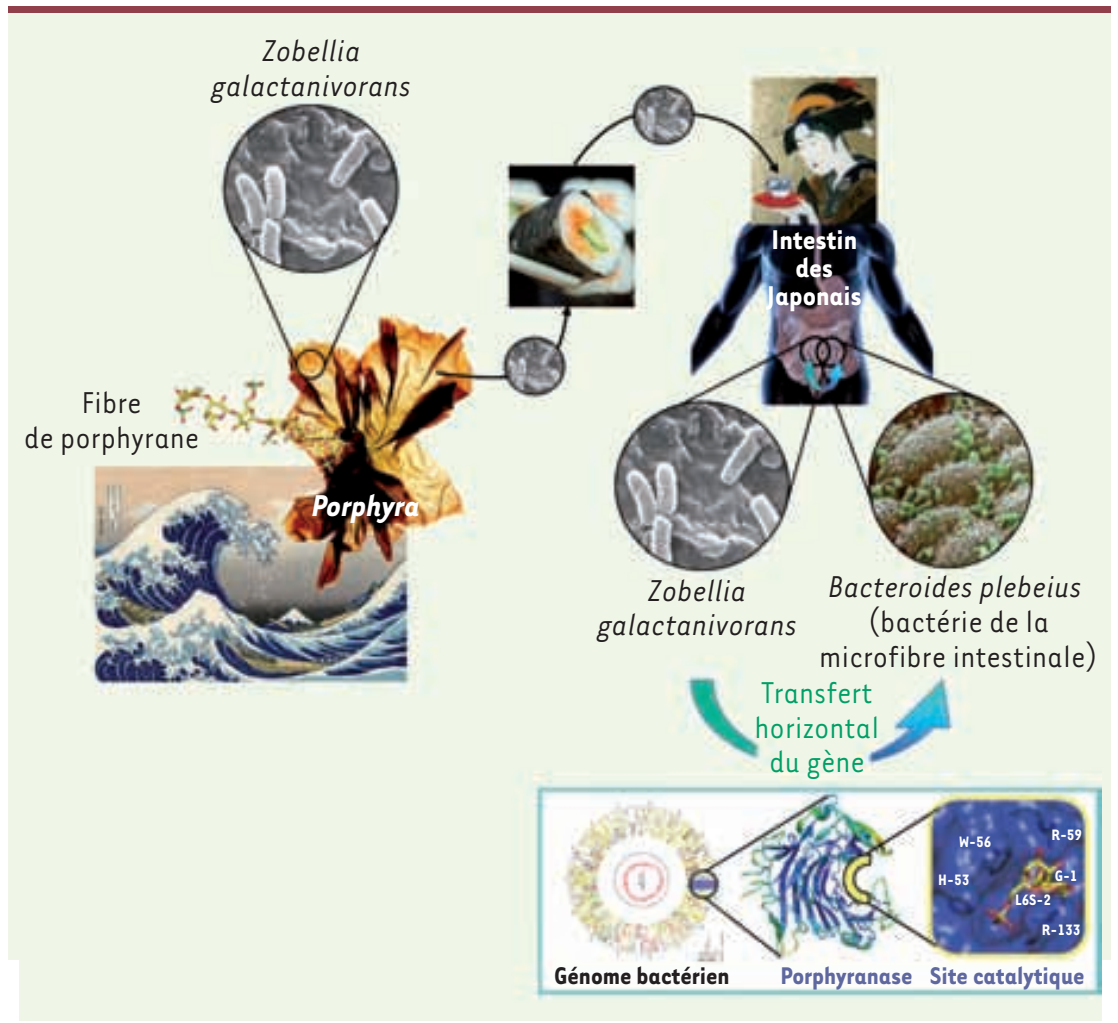

\section{Le transfert}

de gènes de bactéries marines impliquées dans le recyclage de la biomasse algale vers la microflore intestinale des Japonais La cuisine japonaise est particulièrement riche en algues. Ces végétaux marins, qui comprennent les algues vertes, rouges et brunes, produisent des polysaccharides qui n'ont pas d'équivalents dans les plantes terrestres. De nombreuses bactéries marines vivent associées à ces algues, et, parmi ces micro-organismes, on trouve des champions de la dégradation des fibres algales. Dans notre laboratoire «Végétaux marins et biomolécules», une flavobactérie marine, Zobellia galactanivorans, isolée de la surface de l'algue rouge Delesseria sanguinea [8], sert de bactérie modèle pour comprendre les voies métaboliques spécifiques au milieu marin [9]. Depuis peu, nous avons obtenu son génome complet (Barbeyron et al., en préparation). En étudiant la diversité des enzymes spécialisées dans la dégradation des polysaccharides d'algues de Z. galactanivorans,
Figure 1. Photomontage schématique illustrant le chemin le plus probable qui a permis le transfert de gènes des bactéries marines vers les bactéries de la microflore humaine. L'encart schématise la découverte d'une enzyme possédant une nouvelle spécificité de substrat. Origine des images: The Great Wave off Kanagawa de l'artiste japonais Hokusai ; l'algue rouge Porphyra (๔ photo M. Jam); Maki-Sushi (@ photo http://www.maxisciences.com); Geisha peinture sur verre (๔ photo http://nictoo.skynetblogs.be/post/595540/ geisha); microflore et intestin humain (๔ photo Bajzer et al., Nature, 2006).

Le criblage des banques de séquences comme GenBank nous a révélé que les gènes de porphyranases n'existaient que dans des bactéries marines, à l'exception d'une bactérie isolée de la microflore intestinale d'un individu japonais, Bacteroides plebeius. À peine remis de cette surprise, nous nous sommes empressés de consulter les données de métagénomique obtenues à partir de la microflore des Japonais [11] et des Américains [12]. Cette analyse nous a confirmé cette exception: dans les données de «microbiomes» des Japonais, nous avons identifié six gènes codant pour des porphyranases chez six individus différents, alors que dans les «microbiomes» des Américains nous n'en avons trouvé aucun! Compte tenu de la taille de la banque de données métagénomiques, et après vérification avec d'autres gènes témoins [2], cette répartition exclusive s'est avérée statistiquement significative. II restait alors à comprendre l'origine de ces gènes exotiques. En analysant le génome de Bacteroides plebeius, nous avons trouvé que le gène de la porphyranase, ainsi que 10 autres gènes l'entourant, étaient très similaires à des gènes identifiés chez les bactéries marines, et n'étaient pas présents dans les génomes d'autres espèces de Bacteroides intestinaux. Par conséquent, nos analyses ont révélé un transfert de gènes entre une bactérie 
marine ancestrale et une bactérie intestinale spécifique des Japonais! Cette hypothèse est d'autant plus plausible que les algues, et notamment celles du genre Porphyra, représentent une base importante de la nutrition et de la culture culinaire des Japonais, et ce depuis au moins 1000 ans [13]. Une fois ingérées par des Japonais, ces bactéries marines associées aux algues ont ainsi pu entrer en contact avec les bactéries intestinales et leur transférer leurs « ustensiles ». Cet événement de transfert unique est relativement récent dans l'évolution des bactéries intestinales, mais est sans nul doute assez ancien du point de vue humain (quelques centaines ou milliers d'années).

Nos propres bactéries intestinales seraient-elles capables d'acquérir de nos jours les mêmes ustensiles que les bactéries intestinales des Japonais si nous mangions régulièrement des mets à base d'algues crues? Cette question qui nous vient spontanément à l'esprit reste ouverte. En revanche, il est très probable que de tels transferts de gènes entre des bactéries intestinales et des bactéries de l'environnement aient eu lieu tout au long de l'évolution des vertébrés, expliquant la prévalence des enzymes de dégradation de polysaccharides de plantes terrestres dans la microflore des herbivores et omnivores. Cette découverte du «sushi factor» n'est en tout cas que le début d'un champ d'investigation plus vaste de l'évolution de la microflore humaine. $\diamond$

You are what you eat: the sushi factor in the Japanese gut microbiota

\section{CONFLIT D'INTÉRÊTS}

Les auteurs déclarent n'avoir aucun conflit d'intérêts concernant les données publiées dans cet article.

\section{RéFÉRENCES}

1. Sonnenburg JL. Genetic pot luck. Nature 2010; $464: 837-8$.

2. Hehemann JH, Correc G, Barbeyron T, et al. Transfer of carbohydrate-active enzymes from marine bacteria to Japanese gut microbiota. Nature 2010 ; 464 : 908-12.

3. Dethlefsen L, McFall-Ngai M, Relman DA. An ecological and evolutionary perspective on humanmicrobe mutualism and disease. Nature 2007 ; $449: 811-8$.

4. Xu J, Mahowald MA, Ley RE, et al. Evolution of symbiotic bacteria in the distal human intestine. PLoS Biol 2007 ; 5 : el56.
5. Ochman H, Lawrence JG, Groisman EA. Lateral gene transfer and the nature of bacterial innovation. Nature $2000 ; 405$ : 299-304.

6. Ley RE, Lozupone CA, Hamady M, et al. Worlds within worlds: evolution of the vertebrate gut microbiota, Nat Rev Microbiol 2008; 6 : 776-88.

7. Lozupone CA, Hamady M, Cantarel BL, et al. The convergence of carbohydrate active gene repertoires in human gut microbes. Proc Natl Acad Sci USA 2008 ; 105: 15076-81.

8. Barbeyron T, L'Haridon S, Corre E, et al. Zobellia galactanovorans gen. nov., sp. nov., a marine species of Flavobacteriaceae isolated from a red alga, and classification of [Cytophaga] uliginosa (ZoBell and Upham 1944) Reichenbach 1989 as Zobellia uliginosa gen. nov., comb. nov. Int J Syst Evol Microbiol 2001 ; $51: 985-7$.

9. Michel G, Nyval-Collen P, Barbeyron T, Czjzek M, Helbert W. Bioconversion of red seaweed galactans: a focus on bacterial agarases and carrageenases. Appl Microbiol Biotechnol 2006 ; 71: 23-33.

10. Walker A. A glut from the gut: metagenomics takes a giant step forward. Nat Rev Microbiol $2010 ; 8: 315$.

11. Kurokawa K, Itoh T, Kuwahara T, et al., Comparative metagenomics revealed commonly enriched gene sets in human gut microbiomes. DNA Research 2007 ; $14: 169-81$.

12. Turnbaugh PJ, Hamady M, Yatsunenko T, et al. A core gut microbiome in obese and lean twins. Nature 2009; 457: 480-4.

13. K. Nisizawa, H. Noda, R. Kikuchi, et al. The main seaweed foods in Japan. Hydrobiologia $1987 ; 151: 5$.

14. Dauga C, Doré J, Sghir A. La diversité insoupçonnée du monde microbien. Med Sci (Paris) 2005 ; 21 : 290-6.

15. Gilgenkrantz S. Les Japonais et nous. Med Sci (Paris) $2010 ; 26: 808-10$. 